\title{
Correction to: Evaluation of bottom ash slagging risk during combustion of herbaceous and woody biomass fuels in a small-scale boiler by principal component analysis
}

\author{
Thomas Zeng $^{1}$ (D) $\cdot$ Agata Mlonka-Mędrala $^{2} \cdot$ Volker Lenz $^{1} \cdot$ Michael Nelles $^{1,3}$
}

Published online: 22 January 2020

(C) Springer-Verlag GmbH Germany, part of Springer Nature 2020

\section{Correction to: Biomass Conversion and Biorefinery}

https://doi.org/10.1007/s13399-019-00494-2

The original version of this article unfortunately contained a mistake.

The unit in equation 4 was presented incorrectly, "[mol/g]" should be "[mmol/kg]". The equation with the correct unit is given below:

slag index $\operatorname{Al}_{\mathrm{S}}=\left(\frac{\mathrm{Si}+\mathrm{P}+\mathrm{K}}{\mathrm{Ca}+\mathrm{Mg}+\mathrm{Al}}\right) \cdot \mathrm{S}[\mathrm{mmol} / \mathrm{kg}]$
Accordingly, the unit "[mol/g]" should be "[ $\mathrm{mmol} / \mathrm{kg}]$ " in the text, i.e., in the Abstract as well as in chapter 3.3 ("Adaption of the slagging index") and chapter 4 ("Summary and conclusions").

The unit of the x-axis in Fig. 5 (right) should also be corrected which is given below.
Fig. 5 Molar ratio of $(\mathrm{Si}+\mathrm{P}+\mathrm{K}) /$ $(\mathrm{Ca}+\mathrm{Mg})$, left, and $(\mathrm{Si}+\mathrm{P}+\mathrm{K}) /$ $(\mathrm{Ca}+\mathrm{Mg}+\mathrm{Al}) * \mathrm{~S}$, right, versus SSF. Black filled circles: wood pellets and wood chips (objects I and XI to XXVI), black filled squares: W/M pellet blends (objects II to IV), black filled triangles: W/S pellet blends (object IX and $\mathrm{X}$ ), black filled diamond: $\mathrm{M} / \mathrm{S}$ pellet blends (object VI and VII), non filled circles: herbaceous biomass pellets, i.e. $100 \mathrm{M}$ and 100S (object V and VIII).
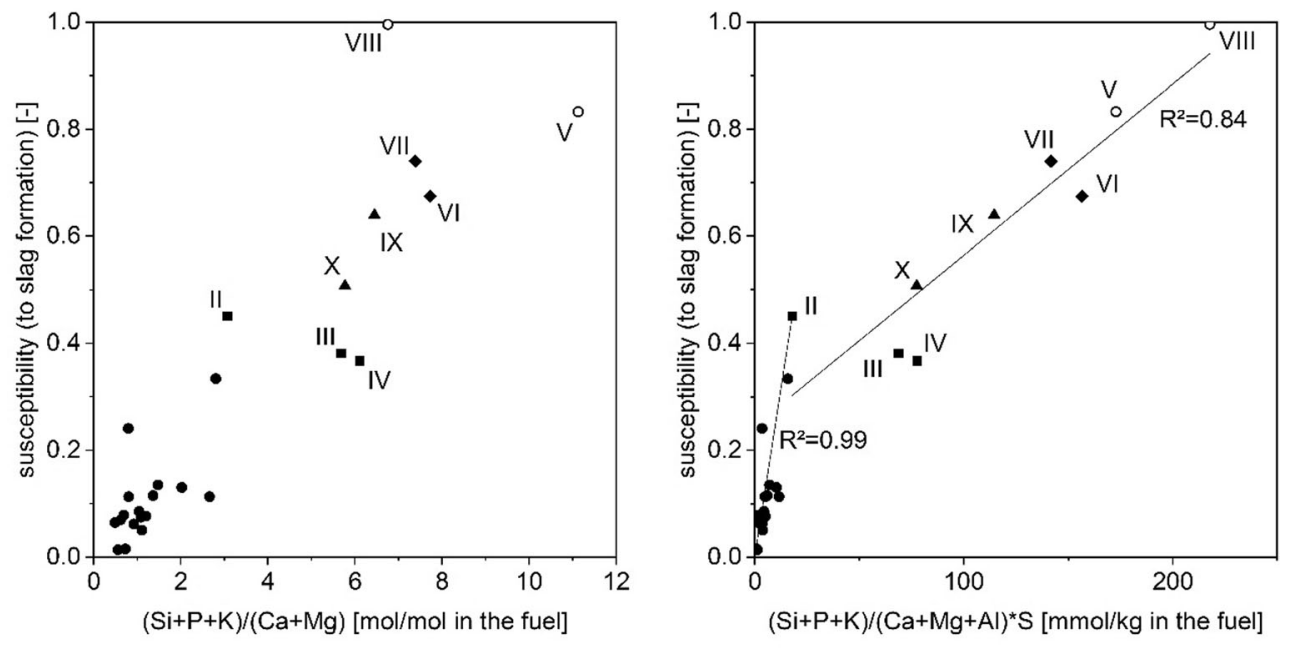

The online version of the original article can be found at https://doi.org/10. 1007/s13399-019-00494-2

Thomas Zeng

thomas.zeng@dbfz.de

1 DBFZ Deutsches Biomasseforschungszentrum gemeinnützige GmbH (DBFZ), Torgauer Straße 116, 04347 Leipzig, Germany
2 Faculty of Energy and Fuels, AGH University of Science and Technology, Mickiewicza 30, 30059 Krakow, Poland

3 Faculty of Agricultural and Environmental Sciences, Chair of Waste and Resource Management, University of Rostock, Justus-von-Liebig-Weg 6, 18059 Rostock, Germany 